\title{
Retraction: Behavior disorders in childhood epilepsy
}

I hereby declare that an analysis of the review article Distúrbios Comportamentais na epilepsia da infância, published in Jornal de Pediatria, revealed sections that are a literal translation of the article Neuropsychiatric aspects of epilepsy in children, by Dunn DW, published in Epilepsy \& Behavior 2003;4(2):101-106.

The publication was not intentional and in no way a violation of faith, since the information which appears in the article was taken from MEDLINE and the name of the author was cited several times, including in the reference list. Unfortunately, one of the early versions of the article was mistakenly submitted. This was a hasty and impulsive act, a consequence of my strenous professional activity. This incident served to make me reflect and reorganize my life.

Thus, I take full responsibility for this event.

Sincerely

Sérgio Antonio Antoniuk

\section{Comments from the Editor}

$\mathrm{H}_{\mathrm{a}}$ Comportamentais na epilepsia da infância, by Antoniuk AS, published in Jornal de Pediatria 2004;80(2 Suppl):S56-S60, the Editorial Board of Jornal de Pediatria has verified that many paragraphs of Mr Antoniuk's article consist of a nonauthorized translation [into Brazilian Portuguese] of the review article "Neuropsychiatric Aspects of Epilepsy in Children," by Dunn DW, published in Epilepsy \& Behavior 2003;4:101-106. Although the author did not omit the bibliographic reference to the article by Dunn, which is cited several times throughout the text, the use of a nonauthorized translation is not acceptable.

After comparing the two articles, the Editorial Board concluded that the review article published in Jornal de Pediatria does not contain any original data from Dunn DW and all the assumptions discussed are known to the scientific community. Nevertheless, the use of previously published texts is not warranted.

Considering this fact, the Editorial Board of Jornal de Pediatria, with agreement of the author, has decided to remove the article from the Journal's website and from all national and international indexing databases. The Board has also agreed to accept the author's retraction. Any further action was not deemed necessary.

We would like to thank Dr. Jj Ortega-Albás from the General Hospital of Castellón, Castellón de la Plana, Spain, for raising the issue. The Editorial Board of Jornal de Pediatria meets every fortnight in order to analyze the articles submitted to the appreciation of our referees, who are highly qualified professionals. In the same manner, the articles published in the supplements are analyzed by each supplement editor. Unfortunately, the resemblance between the two articles went unnoticed. We agree with Dr. OrtegaAlbás in that this event is condemnable from both a scientific and ethical point of view.

The Editorial Board of Jornal de Pediatria and the editors of the supplement Neurobiology of behavior and associated disorders apologize to Epilepsy \& Behavior and to Dr. DW Dunn .

Jornal de Pediatria is an international journal that believes in the globalization of knowledge. The full text of all articles published in Jornal de Pediatria is electronically available in both Portuguese and in English, both in Brazil and worldwide. The use of non-authorized translations and previously published texts is unacceptable and can be easily detected. The Editorial Board of Jornal de Pediatria hopes that unpleasant events such as this will not occur again.

\section{Renato S. Procianoy}

Editor in chief - Jornal de Pediatria 